\title{
Vigilância Sanitária e Atenção Primária à Saúde: dimensões e práticas colaborativas em uma capital
}

\author{
Health Surveillance and Primary Health Care: collaborative \\ dimensions and practices in a capital
}

\author{
Manoel Ribeiro de Sales Neto* \\ Felipe Moreira de Paiva \\ Nadja Mara de Sousa Lopes \\ Cremeilda Dantas de Abrantes \\ Lôbo
}

Ana Paula Soares Gondim
Universidade Federal do Ceará (UFC), Fortaleza, CE, Brasil

\footnotetext{
* E-mail: salesnetomr@gmail.com
}

\section{RESUMO}

Introdução: Postula-se que a Vigilância Sanitária e a Atenção Primária à Saúde desenvolvam práticas colaborativas como comunicação dos riscos e educação em saúde. Objetivo: Descrever a colaboração entre Vigilância Sanitária e Atenção Primária à Saúde em uma capital brasileira. Método: Estudo qualitativo realizado com entrevistas, observação participante e revisão documental. Os dados construídos foram trabalhados com a análise de conteúdo, tendo como referência uma tipologia de colaboração interorganizacional. Resultados: Comprovou-se o não reconhecimento de objetivos comuns. Também dificultam a colaboração a imagem fiscalizatória da Vigilância Sanitária, a formalização exígua das práticas colaborativas e a insuficiência de espaços para discussão de problemas e formação de vínculos. Foi identificado o esporádico desenvolvimento de algumas ações em colaboração, como análises das irregularidades sanitárias das Unidades de Atenção Primária à Saúde, enquanto outras foram sugeridas, incluindo o compartilhamento de informações sobre produtos e serviços. Conclusões: A colaboração entre Vigilância Sanitária e Atenção Primária à Saúde precisa avançar no terreno das práticas, tendo em vista os benefícios que essa proposta pode acarretar.

PALAVRAS-CHAVE: Comportamento Cooperativo; Vigilância Sanitária; Atenção Primária à Saúde

\begin{abstract}
Introduction: It is postulated that Health Surveillance and Primary Health Care develop collaborative practices like communication and health education. Objective: To describe the collaboration between Health Surveillance and Primary Health Care in a Brazilian capital. Method: Qualitative study conducted with interviews, participant observation and document review. The data were worked with Content Analysis, having as reference a typology of interorganizational collaboration. Results: Failure to recognize common goals has been proven. In addition, the supervisory image of Sanitary Surveillance, the weak formalization of collaborative practices and the lack of spaces for discussion of problems and formation of bonds hinder the collaboration. The sporadic development of some collaborative actions was identified, such as analyses of health irregularities of Primary Health Care Units, while other actions were suggested, including sharing information about products and services. Conclusions: The collaboration between Sanitary Surveillance and Primary Health Care needs to advance in the field of practice, considering the benefits that this proposal can bring.
\end{abstract}

KEYWORDS: Cooperative Behavior; Health Surveillance; Primary Health Care 


\section{INTRODUÇ̃̃O}

O surgimento e a manutenção de riscos sanitários, ambientais e comportamentais nos últimos anos tornaram mais complexos os problemas e as necessidades em saúde. É nesse contexto, caracterizado também pelo isolamento do trabalho intelectual, que a interdisciplinaridade demarca sua importância, ao fundamentar o trabalho conjunto para a resolução de problemas que demandam a articulação de saberes.

Como proposta de trabalho interdisciplinar, a prática colaborativa pode ser entendida como o compartilhamento de poder entre os parceiros de trabalho para o alcance de objetivos pactuados ativamente em discussões ou negociações ${ }^{1}$. Esse processo demanda também o reconhecimento do papel do outro na complementaridade das ações em saúde².

A Atenção Primária à Saúde (APS) destaca-se como ambiente favorável às iniciativas de práticas colaborativas ${ }^{3}$, sendo reconhecidas duas configurações que se alternam de acordo com as necessidades dos usuários ou sob outras condições ${ }^{4}$. A primeira é a colaboração em equipe, na qual os trabalhadores buscam apoio entre os próprios componentes da equipe ou nas demais equipes de uma mesma unidade. A segunda é a colaboração em rede e com a comunidade, quando os trabalhadores da equipe procuram apoio em outros serviços e na comunidade. Considerando o último arranjo, abordamos, neste estudo, a colaboração entre a Vigilância Sanitária (Visa) e a APS.

Para a realização satisfatória de seus exercícios, a literatura considera que a Visa precisa fortalecer as relações com os demais entes do Sistema Único de Saúde (SUS) ${ }^{5,6}$. Sua colaboração com a APS é importante para que o saber sanitário dialogue com os conhecimentos da população e dos profissionais da atenção à saúde, mediante informação e comunicação ${ }^{7}$. Além disso, os trabalhadores devem estar aptos a identificar os riscos sanitários em seus territórios de atuação $0^{6}$.

Alguns instrumentos normativos também ressaltam a necessidade de a Visa e a APS atuarem de maneira colaborativa. Por exemplo: a Política Nacional de Vigilância em Saúde recomenda a adoção de serviços que assegurem a integralidade mediante a inserção das vigilâncias, incluindo a sanitária, no âmbito da APS $^{8}$. Por sua vez, a Portaria Federal $n^{\circ} 1.378$, de 9 de julho de $2013^{9}$, postula que a colaboração deve envolver um trabalho condizente com a realidade local, por meio do compartilhamento de tecnologias. Outros documentos que reafirmam a perspectiva colaborativa são a Política Nacional de Atenção Básica (PNAB) ${ }^{10} \mathrm{e}$ o Plano Diretor de Vigilância Sanitária (PDVISA) ${ }^{11}$.

Portanto, questionamos como ocorre, na prática, a colaboração entre Visa e APS, tendo em vista o reconhecimento de sua importância na área teórica da literatura e dos instrumentos normativos. Assim sendo, o objetivo deste escrito foi descrever a colaboração entre Visa e APS em um município.

Estudos que abordam a interação da Visa com demais componentes do SUS, como Rede Cegonha ${ }^{12}$ e Saúde da Mulher ${ }^{13}$, apontaram que o trabalho conjunto não ocorre sistematicamente. Ademais, considera-se que existe integração insuficiente entre a APS e os demais níveis de complexidade ${ }^{14}$, apesar de terem sido constatados avanços na colaboração entre os trabalhadores da equipe de saúde ${ }^{15}$.

Em razão da necessidade ainda existente de superar a fragmentação no SUS ${ }^{16}$, é relevante abordar os fatores que influenciam o desenvolvimento das ações colaborativas. Esse debate é útil na medida em que atende à demanda de mapeamento da interface da Visa com Políticas de Saúde ${ }^{17}$ e pode contribuir para o estabelecimento ou fomento de práticas colaborativas.

\section{MÉTODO}

Este é um estudo descritivo com abordagem qualitativa, realizado com trabalhadores e gestores da Visa e da APS para descrever a colaboração entre esses núcleos no município de Fortaleza (Ceará).

A capital cearense tem sua administração municipal dividida territorialmente em seis secretarias regionais (SR). A Secretaria Municipal de Saúde (SMS) planeja e coordena as práticas de APS e Visa por intermédio da Célula de Atenção Primária à Saúde e da Célula de Vigilância Sanitária, respectivamente. Esta juntamente às Células de Vigilância Epidemiológica, à Vigilância em Saúde do Trabalhador, de Sistemas de Informação e à Análise em Saúde e de Vigilância Ambiental e de Riscos Biológicos compõem a Coordenadoria de Vigilância em Saúde.

Classificamos os sujeitos do estudo em duas categorias profissionais: trabalhadores ou gestores. Em relação à Visa, consideramos como trabalhadores aqueles que ocupam cargos de fiscal municipal, atuando na Coordenadoria Regional de Saúde (CORES) de cada SR. Alguns deles são graduados em cursos relacionados às áreas de atuação da Visa (Nutrição, Engenharia de Alimentos, Enfermagem, Odontologia, Medicina, Farmácia, Química e Medicina Veterinária), enquanto outros possuem nível médio ou graduação em outros cursos. Classificamos como gestores os profissionais que coordenam esses trabalhadores, ocupando os cargos de autoridades sanitárias ou coordenadores.

Para a APS, identificamos como trabalhadores das equipes da Estratégia Saúde da Família (ESF), os médicos, enfermeiros e odontólogos, bem como os que atuam como agentes de vigilância em saúde. Esses trabalhadores estão distribuídos nas seis SR, onde exercem funções nas Unidades de Atenção Primária à Saúde (UAPS). Consideramos como gestores os profissionais que coordenam esses trabalhadores, atuando como articuladores ou coordenadores.

Participaram do estudo trabalhadores e gestores com pelo menos um ano de atuação. A coleta de dados ocorreu nos meses de fevereiro de 2016 a março de 2017, por meio de entrevista semiestruturada, revisão documental e observação participante. A entrevista é uma técnica que possibilita a obtenção de informações reflexivas dos sujeitos sobre a realidade vivenciada ${ }^{18}$. 
0 roteiro utilizado como guia das entrevistas foi composto por questões norteadoras relativas à colaboração entre Visa e APS, como práticas desenvolvidas, relacionamento entre profissionais, reconhecimento de objetivos compartilhados e dos escopos de práticas, além das dificuldades.

Antes das entrevistas, os participantes conheceram os objetivos do estudo, receberam garantias de anonimato e desistência e assinaram um Termo de Consentimento Livre e Esclarecido. Os áudios gravados eletronicamente foram posteriormente transcritos em sua integralidade. Após cada entrevista, utilizamos fichas de caracterização para obter os seguintes indicativos: sexo (masculino/ feminino), idade (anos), nível de escolaridade (anos) e tempo de serviço no cargo atual (anos).

A revisão de documentos permitiu complementar as entrevistas com informações sobre o contexto em que ocorriam os processos de interesse ${ }^{18}$. Neste estudo, revisamos documentos oficiais que pudessem tratar do planejamento de procedimentos colaborativos, como o Plano Municipal de Saúde de Fortaleza ${ }^{19}$ e o Plano de Ações da Visa de Fortaleza ${ }^{20}$.

Durante a observação participante, o pesquisador se posiciona como observador de determinada circunstância em relação direta com seus interlocutores ${ }^{18}$. Nesse sentido, observamos as atuações que, durante as entrevistas prévias, foram indicadas como exemplos de procederes colaborativos. Recorremos a um roteiro para direcionamento dos aspectos que deveriam ser observados (ambiente, comportamento e relacionamento dos sujeitos e descrição da atividade), bem como um diário de campo para registro das informações.

Os dados coletados foram trabalhados com amparo na análise de conteúdo ${ }^{21}$. A operacionalidade dessa técnica foi dividida nas seguintes etapas: pré-análise, que tem as finalidades de exploração do material e elaboração do corpus de análise; definição de hipóteses provisórias sobre o objeto estudado; determinação das unidades de registro dos temas identificados; e elaboração das categorias, entendidas como a reunião de elementos constitutivos de um conjunto.

As categorias foram elaboradas em cortejo a uma tipologia de colaboração interprofissional e interorganizacional desenvolvida em serviços de APS canadenses². Essa tipologia denota quatro dimensões, contendo indicadores referentes a aspectos colaborativos (Quadro).

No Brasil, vários estudos empregaram a referida tipologia no contexto da saúde, por exemplo, para investigar a colaboração em programas de residência multiprofissional ${ }^{22}$, assim como entre trabalhadores do Programa Saúde na Escola ${ }^{23}$. Este estudo foi autorizado pela SMS de Fortaleza e aprovado pelo Comitê de Ética em Pesquisa da Universidade Federal do Ceará (Parecer $\mathrm{n}^{\circ}$ 1.292.557).

\section{RESULTADOS E DISCUSSÃO}

Realizamos 44 entrevistas, sendo 19 com trabalhadores e quatro com gestores da Visa e as demais com 16 trabalhadores e cinco gestores da APS. Salientamos que a maioria dos entrevistados foi do sexo feminino, possuía especialização e tinha idade e tempo de serviço variando, respectivamente, de 30 a 62 anos e de um a 38 anos.

\section{Objetivos e visão compartilhados}

A apropriação de objetivos compartilhados pelos profissionais e a orientação centrada nos usuários dos serviços ${ }^{2}$ constituem essa categoria.

De acordo com alguns entrevistados, Visa e APS possuem objetivos específicos e compartilhados. Os primeiros são inerentes à dimensão fiscalizatória da Visa e à recuperação da saúde desenvolvida pela APS. Os objetivos compartilhados reconhecidos pelos entrevistados são a educação em saúde, a prevenção de doenças e a promoção da saúde (Figura 1).

Quadro. Dimensões e indicadores do modelo de colaboração interprofissional e interorganizacional.

\begin{tabular}{|c|c|c|}
\hline Dimensão & Indicador & Descrição \\
\hline \multirow{2}{*}{$\begin{array}{l}\text { Objetivos e visão } \\
\text { compartilhados }\end{array}$} & Objetivos & Identificação e compartilhamento de objetivos comuns. \\
\hline & $\begin{array}{l}\text { Orientação centrada no } \\
\text { usuário }\end{array}$ & Pactuação dos interesses, rompendo com a convergência parcial de interesses. \\
\hline \multirow{2}{*}{ Internalização } & Convivência mútua & $\begin{array}{l}\text { Os profissionais devem se conhecer pessoal (valores e competências) e profissionalmente } \\
\text { (atividades profissionais). }\end{array}$ \\
\hline & Confiança & Confiança nas competências e nas habilidades para assumir responsabilidades. \\
\hline \multirow{4}{*}{ Governança } & Centralidade & Direção clara e explícita para coordenação das ações no sentido da colaboração. \\
\hline & Liderança & Liderança local que possibilite a participação de todos na decisão. \\
\hline & Suporte para inovação & Educação permanente para o desenvolvimento de competências. \\
\hline & Conectividade & Conexão entre os profissionais e espaços para discussão e estabelecimento de vínculos. \\
\hline \multirow{2}{*}{ Formalização } & $\begin{array}{l}\text { Ferramentas de } \\
\text { formalização }\end{array}$ & Pactuação por via de acordos, protocolos e outros meios. \\
\hline & Troca de informações & $\begin{array}{c}\text { Existência e apropriação do uso de estrutura de informação que permitam a rápida e completa } \\
\text { troca de informação. }\end{array}$ \\
\hline
\end{tabular}

Fonte: Adaptado². 


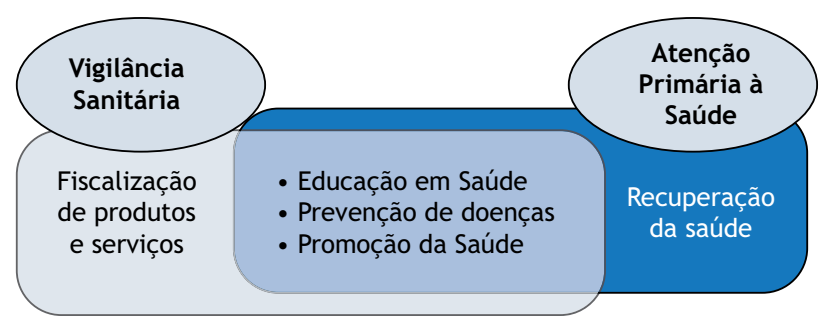

Fonte: Elaborada pelos autores, 2020.

Figura 1. Objetivos específicos e compartilhados da Vigilância Sanitária e da Atenção Primária à Saúde. Fortaleza, 2017.

Além de cobrar as licenças sanitárias da gente? [risos] A Vigilância Sanitária tem como função fiscalizar os estabelecimentos de saúde e os comércios. Ela é o órgão fiscalizador, pode apreender, pode interditar, ela tem esse poder (Gestor da APS).

Esse trecho de entrevista representa, entre alguns entrevistados da APS, o entendimento estritamente fiscalizatório dos objetivos da Visa. Essa perspectiva remonta ao modelo da Visa tradicional, caracterizado pela centralização na imagem do fiscal que, mediante a inspeção, verifica o cumprimento da legislação ${ }^{6}$. As práticas relacionadas à dimensão fiscalizatória são essenciais para a proteção à saúde, mas defendemos o entendimento segundo o qual a Visa não deve estar restrita a essa dimensã $0^{5,6}$.

"Nem eu sei as funções da Vigilância Sanitária, mas eu sei as da Vigilância Epidemiológica" (Trabalhadora da APS). Outros trabalhadores da APS assumem seu desconhecimento em relação aos objetivos da Visa. Fatores que possivelmente contribuem para essa colocação são as divergências dessa vigilância atinentes aos demais núcleos do SUS no que se refere aos processos de descentralização e de pactuação $0^{24} \mathrm{e}$ da preferência que se dá às atividades assistenciais em detrimento das coletivas ${ }^{16}$.

Também constatamos que os trabalhadores da APS demonstram maior familiaridade com a Vigilância Epidemiológica (VE), que possui uma rotina de trabalhos colaborativos mais formalizada e sistematizada, quando comparada à Visa. Além disso, o Sistema Nacional de Vigilância Sanitária estruturou-se e descentralizou-se mais tardia e lentamente do que o de $\mathrm{VE}^{25}$.

À vista desses dados, defendemos o ponto de vista consoante o qual, para fomentar a identificação e a apropriação dos objetivos compartilhados, é primordial divulgar para os trabalhadores e gestores da APS a ideia de que a Visa pode contribuir na prevenção de doenças, assim como na promoção e na educação em saúde. Isso também atenderia à necessidade que se tem de constituir uma imagem da Visa com potencial de contribuir com as demais políticas de saúde ${ }^{13}$ e mais próxima dos usuários.

Em relação à orientação centrada nos usuários, os entrevistados consideram que a Visa se relaciona indiretamente com aqueles através das inspeções nas UAPS e nos demais espaços de interesse sanitário e da proposição de medidas para redução do risco. Existe, entretanto, o reconhecimento de que não são realizadas atividades em contato direto com os usuários, sendo propostas, para redução deste distanciamento, práticas educativas direcionadas ao reconhecimento de produtos e serviços que oferecem riscos à saúde.

A educação em saúde possibilitaria aos usuários um melhor reconhecimento dos riscos sanitários, bem como faria com que os trabalhadores da Visa se aproximassem mais das dimensões culturais e simbólicas construídas socialmente sobre a saúde. Destacamos que as práticas sanitárias devem estar associadas às interpretações locais sobre os problemas de saúde ${ }^{5,7}$. A educação em saúde, ferramenta para a promoção da saúde e prevenção de doenças, é recomentada também pelo PDVISA ${ }^{11}$ e pela $\mathrm{PNAB}^{10}$.

A Lei da Liberdade Econômica, de 20 de setembro de 2019, introduziu modificações no gerenciamento dos riscos ${ }^{26}$. As atividades classificadas como sendo de baixo risco sanitário, como as desenvolvidas, entre outros, por lanchonetes, açougues e academias de ginástica, de acordo com a Instrução Normativa da Agência Nacional de Vigilância Sanitária (Anvisa) $n^{\circ} 16$, de 26 de abril de $2017^{27}$, podem ser desenvolvidas sem a obrigatoriedade de licenciamento sanitário. Consequentemente, estabelecimentos que desenvolvam apenas atividades de baixo risco passaram a poder funcionar sem inspeção prévia da Visa. Esse cenário demanda que a população seja ciente dos riscos sanitários aos quais pode ser exposta, sendo capaz de reconhecer situações potencialmente perigosas à saúde. Essa consciência sanitária pode ser construída ou aperfeiçoada com a aproximação entre Visa e APS em busca de seus objetivos compartilhados.

\section{Internalização}

Essa categoria cuida do conhecimento em relação à finalidade de ações da Visa e da APS, bem assim da consciência dos trabalhadores sobre a interdependência de suas práticas².

Eu não posso dizer o que realmente os profissionais da APS estão fazendo, porque eu não estou lá dentro das unidades de saúde, mas creio que eles estão fazendo o que as equipes da Estratégia Saúde da Família normalmente fazem (Trabalhador da Visa).

Os trabalhadores da Visa assumem que desconhecem os operadores da APS e os trabalhos por eles desenvolvidos. Essa configuração dificulta a colaboração ${ }^{2}$, pois o conhecimento do trabalho do outro é essencial para que sejam propostas operações que possam ser desenvolvidas de maneira colaborativa. Além desse conhecimento, a colaboração requer dos trabalhadores a vontade de cooperar ${ }^{3}$.

“Para a Atenção Primária à Saúde, a Vigilância Sanitária é vista como o bicho papão que está na Unidade de Atenção Primária à Saúde apenas para punir" (Trabalhador da APS). Os trabalhadores da Visa são entrevistos com certa desconfiança pela APS, como aqueles que possuem as missões apenas de apontar o que está errado e de possivelmente aplicar as devidas punições, o que constitui outra dificuldade para a convivência mútua. A representação da Visa como essencialmente fiscalizatória e potencialmente punitiva pode ter como fatores contributivos o 
seu distanciamento histórico com relação às demais atividades de saúde ${ }^{24}$ e sua atuação essencialmente fiscalizatória. Essa situação, na medida em que pode provocar rejeição à Visa, não contribui para o estabelecimento de um clima de trabalho provedor da colaboração ${ }^{28}$ e da confiança mútua.

Em 2015, foi promovido pela Anvisa um ciclo de debates que contou com a participação de representantes do Ministério da Saúde, de instituições estaduais e municipais de Visa, do setor regulado e da sociedade civil ${ }^{17}$. O Fórum Nacional que encerrou o ciclo consolidou os debates regionais ocorridos previamente em todo o país e apontou como desafio para o contexto sanitário brasileiro a dificuldade de integração entre Visa e outras ações da saúde. Isso ratifica o distanciamento que constatamos entre os trabalhadores deste estudo como reflexo da conjuntura reconhecida nacionalmente. Entre as consequências dessa situação, o relatório aponta a atitude competitiva e não colaborativa ${ }^{17}$.

Malgrado o desconhecimento em relação ao escopo de práticas, os entrevistados identificaram o desenvolvimento dos seguintes movimentos colaborativos: inspeções sanitárias nas UAPS; reuniões sobre as condições sanitárias das UAPS; análise de projetos de reforma ou construção das UAPS; e combate às arboviroses (Figura 2). A primeira, realizada pelos trabalhadores da Visa, iniciou-se com a análise do cumprimento da legislação sanitária, sendo finalizada com a lavratura e apresentação de termos contendo as irregularidades sanitárias identificadas.

As inspeções nas Unidades de Atenção Primária à Saúde são uma forma bem óbvia de colaboração entre Vigilância Sanitária e a Atenção Primária à Saúde. Nesses momentos é visto se as normas estão sendo cumpridas, para que a população seja atendida da forma mais segura (Trabalhador da Visa).

Esse exercício é de grande importância para a proteção à saúde, mas possui caráter essencialmente fiscalizatório, permeado pela hierarquia de poder entre um ente fiscalizador e outro fiscalizado. Isso dificulta o estabelecimento de experiências colaborativas, pois essas demandam relações horizontais e participação ativa ${ }^{1}$. Outro estudo também evidencia o entendimento de que as inspeções são uma modalidade de colaboração ${ }^{12}$.

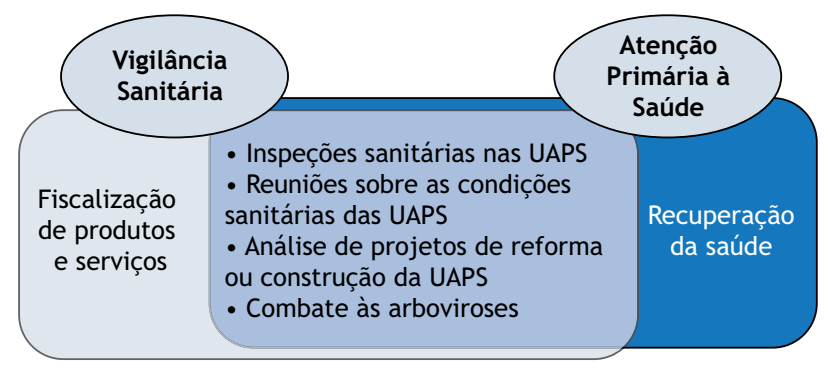

Fonte: Elaborada pelos autores, 2020.

UAPS: Unidades de Atenção Primária à Saúde.

Figura 2. Atividades específicas e compartilhadas desenvolvidas pela Vigilância Sanitária e pela Atenção Primária à Saúde. Fortaleza, 2017.
Das reuniões - cujos objetivos conformam analisar irregularidades constatadas durante as inspeções em UAPS - participaram gestores e trabalhadores da Visa, bem como gestores da APS. Observamos que ambos os núcleos contribuem para o debate e apontaram possíveis soluções para os problemas. Percebemos, todavia, como necessária a participação dos trabalhadores da APS nesses momentos, considerando que eles possuem relação com a pauta discutida e podem enriquecer o labor colaborativo com o oferecimento de outras perspectivas. Para que ocorra a colaboração, todos os membros devem ser envolvidos na tomada de decisão, em um ambiente confiável que permita a expressão de desacordos e diferenças ${ }^{29}$.

Várias UAPS do município estudado foram reformadas ou construídas nos últimos anos. Alguns gestores explicitaram que solicitaram a avaliação das obras pelos trabalhadores da Visa, apesar de os primeiros reconhecerem que algumas das modificações sugeridas pelos segundos não foram aceitas. Essas avaliações, descritas em outro estudo ${ }^{12}$, são importantes para prevenir riscos sanitários, uma das finalidades da Visa.

Durante as avaliações das instituições de longa permanência de idosos, os trabalhadores da Visa analisam as condições sanitárias desses estabelecimentos, enquanto os demais investigam ocorrências de maus-tratos aos idosos. Ressaltamos que tal fato acontece para atender demandas do Ministério Público do Ceará, e não por uma iniciativa dos gestores ou trabalhadores.

O aumento de casos de dengue, zika e chikungunya é considerado como estimulador de ações colaborativas no âmbito da APS $^{15}$. Constatamos que o combate ao mosquito transmissor na capital estudada tem a participação dos trabalhadores da Visa para a resolução de um problema que afeta a população atendida pela APS. Esse exercício consiste na autuação dos estabelecimentos comerciais que registram reincidência na detecção de focos do inseto. 0 problema das arboviroses é complexo pelo fato de receber influência de fatores diversos. Consequentemente, sugerimos que a Visa, arrimada no monitoramento epidemiológico, adote procedimentos que, em colaboração com a APS, superem o caráter fiscalizatório implantado.

Em relação à periodicidade, os entrevistados consideram que as atuações colaborativas são eventuais, ocorrendo quando demandadas por outro órgão ou como respostas a algum problema específico. Outros estudos também destacaram o caráter esporádico da integração entre Visa e outros componentes do SUS ${ }^{12,13}$. Entendemos que a continuidade (em vez da eventualidade) das práticas colaborativas possibilitaria o fortalecimento de vínculos e a sistematização de rotinas de trabalho, contribuindo para a garantia da integralidade.

\section{Governança}

Essa categoria diz respeito às ferramentas adotadas pela gestão para promoção da colaboração².

"Nós somos estranhos, embora pertençamos ao mesmo município e à mesma secretaria, a gente não se reúne pra refletir sobre os problemas de saúde e pensar em estratégias" (Trabalhador da 
Visa). Entre os fatores que potencializam a conectividade, destacamos o compartilhamento dos espaços físicos e o estímulo ao diálogo ${ }^{2}$. Constatamos que gestores e trabalhadores fazem parte da mesma secretaria e compartilham as mesmas salas ou salas contíguas nas CORES. Tais espaços, contudo, não são rotineiramente aproveitados para o estabelecimento da conectividade entre os trabalhadores. Isso significa exprimir que o diálogo é estabelecido, principalmente, durante as ações de colaboração.

Entre os gestores, foi percebido maior grau de conectividade, pois existem diálogos e vínculos entre eles nos encontros periódicos, quando são discutidas as ações de cada núcleo. Isso demonstra que a conectividade acontece no nível da gestão, mas necessita ser intensificada no plano dos trabalhadores. Com amparo nesse fato, entendemos oportuno destacar a ideia de que, para haver colaboração no sentido de tomar decisões em conjunto com o objetivo de resolver problemas comuns, são essenciais as oportunidades frequentes de encontros e discussões horizontais ${ }^{2}$.

"A Vigilância Sanitária nunca veio aqui na Unidade de Atenção Primária à Saúde para propor alguma colaboração" (Trabalhador da APS). Entre os fatores que comprometem a conectividade, também identificamos a falta de iniciativa para colaboração. Esse tipo de comportamento leva ao isolamento dos distintos saberes, podendo ser revertido com o convite à colaboração e com a divulgação das diretrizes, valores e compromissos da Visa ${ }^{30}$.

Cabe ressaltar, ainda, que não são reconhecidos pelos entrevistados lideranças ou direcionamentos claros e explícitos para a colaboração, exceto para as atividades colaborativas já desenvolvidas. Relativamente ao suporte para inovação, deixaram de ser identificadas estratégias de formação interdisciplinar que envolvessem trabalhadores da Visa e da APS.

\section{Formalização}

A oficialização das práticas colaborativas e o compartilhamento de informações compõem essa categoria ${ }^{2}$. Verificamos que as reuniões para o exame das irregularidades sanitárias das UAPS são previstas no Plano de Ações da Visa local ${ }^{20}$, em que estão programados encontros anuais envolvendo apenas três das seis SR pertencentes ao município estudado. Ressaltamos, todavia, que momentos como esses deveriam acontecer com maior periodicidade para que fossem possíveis o fortalecimento dos vínculos e o debate acerca dos demais aspectos sanitários que demandam atuação conjunta, como educação em saúde e riscos potenciais decorrentes da utilização de produtos e serviços.

Outro fato trazido como ressalto é a falta de se prever a colaboração entre Visa e APS no Plano Municipal de Saúde do Município $^{19}$ examinado. Assim sendo, a colaboração entre esses núcleos ainda não é totalmente formalizada, contribuindo para o seu distanciamento. Na contextura nacional, entretanto, existem regulamentações que propõem a colaboração entre Visa e APS ${ }^{9,10,11}$. A implementação prática do que é proposto pelas políticas depende das relações de poder instituídas, uma vez que ditas políticas são formuladas por grupos com interesses diversos no decurso do tempo ${ }^{31}$.
Os entrevistados reconhecem que a formalização parcial das ações colaborativas é uma dificuldade, fato demonstrativo de que há um limite imposto pelo planejamento, impedindo a execução de outras atividades além daquelas oficializadas, o que corrobora o achado de outro estudo ${ }^{12}$.

"A maior dificuldade é a grande demanda de atividades que cada um tem que desenvolver. Isso acaba limitando o nosso tempo e impedindo a aproximação com a Vigilância Sanitária" (Gestor da APS). Além disso, existe a grande demanda de atividades específicas que devem ser realizadas, como fiscalização de produtos e serviços para a Visa e consultas eletivas para a APS. Alguns gestores reconhecem que essas demandas consomem a maior parte do tempo dos trabalhadores, de modo que não haveria disponibilidade para o desenvolvimento de exercícios em colaboração.

Esses indicativos reafirmam o distanciamento entre o que é formulado centralmente nas políticas e aquilo efetivamente realizado no plano das ações. A atuação eminentemente fiscalizatória é incompatível com o entendimento expresso, no PDVISA e na literatura pertinente, de que deveriam também ser desenvolvidas pela Visa atividades de promoção e educação em saúde, envolvendo a população e as demais ações do SUS $5,6,7,11$.

Além dos momentos nos quais desenvolvem alguns procedimentos colaborativos, Visa e APS poderiam também compartilhar várias informações, pois uma detém dados de interesse da outra. Isso poderia aumentar a efetividade do trabalho desenvolvido, uma vez que as informações a serem compartilhadas são importantes para que ambos os segmentos conheçam melhor o território sobre o qual atuam. Outros autores também sugerem esse tipo de atividade ${ }^{31}$.

Por exemplo, a atuação da Visa em resposta às demandas da APS por investigações de produtos ou serviços possivelmente irregulares ou causadores de doenças fortalece o papel da primeira na proteção à saúde. Trabalhando isoladamente, fica muito mais difícil para essa vigilância identificar eventos adversos, possivelmente associados ao uso de produtos ou serviços ${ }^{16}$.

Ademais, os entrevistados da Visa argumentam que atuam apenas nos espaços legalizados, uma vez que, em sua maioria, as inspeções são efetuadas em estabelecimentos que dão entrada nos processos de Licença Sanitária. O compartilhamento de informações com a APS possibilitaria à Visa atuar nos espaços onde ainda não o faz, o que se torna mais importante depois da desobrigação de licenciamento para as atividades de baixo risco sanitário ${ }^{26,27}$.

\section{CONCLUSÕES}

Em razão da importância expressa no âmbito teórico da literatura e dos instrumentos normativos, consideramos que a colaboração entre Visa e APS necessita avançar sob o prisma prático, conquanto tenhamos notado o desenvolvimento eventual de algumas práticas colaborativas. As dimensões do modelo de colaboração interprofissional e interorganizacional ${ }^{2}$ permitiram a identificação de processos que precisam ser implantados ou intensificados para que se caminhe no sentido da colaboração. 
Os resultados do estudo também nos permitem ratificar o entendimento de que a colaboração tem o potencial de trazer inúmeros benefícios. Para a Visa, a colaboração atenderia às necessidades de reorientar o seu trabalho, em ultrapasse à dimensão fiscalizatória, de superar o seu tradicional isolamento e de desconstituir sua representação potencialmente punitiva perante a população e os profissionais da atenção à saúde. Para a APS, a colaboração representa o enriquecimento da territorialização, com a inclusão da perspectiva da Visa sobre os riscos sanitários e o apoio na educação em saúde e na promoção da saúde. Para a população, a integração contribuirá, decerto, para o seu empoderamento no que concerne ao uso de produtos e serviços que podem trazer riscos à saúde.

Reconhecemos que outros fatores não abordados também podem influenciar o decurso de colaboração, tais como financiamento, aspectos políticos e interesse dos trabalhadores. Com o intuito de aprofundar o estudo da intenção colaborativa, sugerimos investigações que também explorem meios de trabalho e modelos em gestão.

\section{REFERÊNCIAS}

1. Feeley N, Gottlieb NN, Dalton C. The collaborative partnership approach to care: a delicate balance. Toronto: Elsevier Mosby; 2005.

2. D’Amour D, Goulet L, Labadie JF, Martin-Rodriguez LS, Pineault R. A model and typology of collaboration between professionals in healthcare organizations. BMC Health Serv Res. 2008;8:1-14. https: / / doi.org/10.1186/1472-6963-8-188

3. Peduzzi M, Agreli HF. Trabalho em equipe e prática colaborativa na atenção primária à saúde. Interface. 2018;22(2):1525-34. https://doi.org/10.1590/1807-57622017.0827

4. Agreli HLF. Prática interprofissional colaborativa e clima do trabalho em equipe na atenção primária à saúde [tese]. São Paulo: Universidade de São Paulo; 2017.

5. Chagas MF, Villela WV. Vigilância sanitária e promoção da saúde: apontamentos para além da regulação e controle. Vigil Sanit Debate. 2014;2(3):30-6. https://doi.org/10.3395/vd.v2i3.178

6. Costa EA. 0 trabalhador de vigilância sanitária e a construção de uma nova vigilância: fiscal ou profissional de saúde? In: Costa EA, organizadora. Vigilância sanitária: desvendando o enigma. Salvador: Universidade Federal da Bahia; 2008. p. 77-90.

7. O'Dwyer G, Tavares MFL, Seta MH. O desafio de operacionalizar as ações de vigilância sanitária no âmbito da promoção da saúde e no locus saúde da família. Interface. 2007;11(23):467-84. https: / / doi.org/10.1590/S1414-32832007000300006

8. Ministério da Saúde (BR). Resolução $N^{\circ} 588$, de 12 de julho de 2018. Institui a política nacional de vigilância em saúde (PNVS). Diário Oficial União. 13 ago 2018.

9. Ministério da Saúde (BR). Portaria $N^{\circ} 1.378$, de 9 de julho de 2013. Regulamenta as responsabilidades e define diretrizes para execução e financiamento das ações de vigilância em saúde pela união, estados, Distrito Federal e municípios, relativos ao Sistema Nacional de Vigilância em Saúde e Sistema Nacional de Vigilância Sanitária. Diário Oficial União. 12 jul 2013.

10. Ministério da Saúde (BR). Portaria No 2.436, de 21 de setembro de 2017. Aprova a política nacional de atenção básica, estabelecendo a revisão de diretrizes para a organização da atenção básica, no âmbito do sistema único de saúde (SUS). Diário Oficial União. 22 set 2017.

11. Agência Nacional de Vigilância Sanitária - Anvisa. Plano diretor de vigilância sanitária. Brasília: Agência Nacional de Vigilância Sanitária; 2007.

12. Fernandes RZS, Vilela MFG. Estratégias de integração das práticas assistenciais de saúde e de vigilância sanitária no contexto de implementação da rede cegonha. Cienc Saude Coletiva. 2014;19(11):4457-66. https://doi.org/10.1590/1413-812320141911.21662013

13. Maia C, Guilhem D, Lucchese G. Integração entre vigilância sanitária e assistência à saúde da mulher: um estudo sobre a integralidade no SUS. Cad Saude Publica. 2010;26(4):682-92. https://doi.org/10.1590/S0102-311X2010000400011

14. Santos AM, Giovanella L. Gestão do cuidado integral: estudo de caso em região de saúde da Bahia, Brasil. Cad Saude Publica. 2016;32(3):1-15. https://doi.org/10.1590/0102-311X00172214

15. Escalda P, Parreira CMSF. Dimensões do trabalho interprofissional e práticas colaborativas desenvolvidas em uma unidade básica de saúde, por equipe de saúde da família. Interface. 2018;22(Supl.2):1717-27. https://doi.org/10.1590/1807-57622017.0818

16. Maia C, Guilhem D. A política de saúde brasileira: principais debates e desafios e interface desses com a vigilância sanitária. Vigil Sanit Debate. 2015;3(4):30-8. https://doi.org/10.3395/2317-269x.00459

17. Agência Nacional de Vigilância Sanitária - Anvisa. Ciclo de debates em vigilância sanitária: desafios e tendências: relatório do fórum nacional. Brasília: Agência Nacional de Vigilância Sanitária; 2016.

18. Minayo MCS. Trabalho de campo: contexto de observação, interação e descoberta. In: Minayo MCS, organizadora. Pesquisa social. 34a ed. Petrópolis: Vozes; 2015. p. 61-77.

19. Secretaria Municipal da Saúde de Fortaleza. Plano municipal de saúde de Fortaleza 2014-2017. Fortaleza: Secretaria Municipal da Saúde de Fortaleza; 2014.

20. Secretaria Municipal da Saúde de Fortaleza. Plano de ação 2016 vigilância sanitária. Fortaleza: Secretaria Municipal da Saúde de Fortaleza; 2015.

21. Bardin L. Análise de conteúdo. São Paulo: 70; 2011. 
22. Arruda GMMS, Barreto ICHC, Ribeiro KG, Frota AC. The development of interprofessional collaboration in different contexts of multidisciplinary residency in family health. Interface. 2018;22(Supl.1):1309-23. https://doi.org/10.1590/1807-57622016.0859

23. Dias MSA, Vieira FMBR, Silva LCC, Vasconcelos MIO, Machado MFAS. Colaboração interprofissional no projeto saúde e prevenção na escola. Cienc Saude Coletiva. 2016;21(6):1789-98. https://doi.org/10.1590/1413-81232015216.08112016

24. Lucena RCB. A descentralização da vigilância sanitária: trajetória e descompasso. Rev Adm Publica. 2015;49(5):1107-20. https://doi.org/10.1590/0034-7612137128

25. Seta MH, Dain S. Construção do sistema brasileiro de vigilância sanitária: argumentos para debate. Cienc Saude Coletiva. 2010;15(Supl.3):3307-17. https://doi.org/10.1590/S1413-81232010000900002

26. Brasil. Lei $N^{\circ} 13.874$, de 20 de setembro de 2019. Institui a declaração de direitos de liberdade econômica; estabelece garantias de livre mercado; altera as leis $\mathrm{N}^{\circ} 10.406$, de 10 de janeiro de 2002 (código civil), $N^{\circ} 6.404$, de 15 de dezembro de 1976, № 11.598, de 3 de dezembro de 2007, $\mathrm{N}^{\circ} 12.682$, de 9 de julho de 2012, № 6.015, de 31 de dezembro de 1973, № 10.522, de 19 de julho de 2002, № 8.934 , de 18 de novembro 1994 , o decreto-lei $N^{\circ} 9.760$, de 5 de setembro de 1946 e a consolidação das leis do trabalho, aprovada pelo decretolei $\mathrm{N}^{\circ} 5.452$, de 1 de maio de 1943; revoga a lei delegada $\mathrm{N}^{\circ} 4$, de 26 de setembro de 1962, a lei $\mathrm{N}^{\circ} 11.887$, de 24 de dezembro de 2008 , e dispositivos do decreto-lei $\mathrm{N}^{\circ} 73$, de 21 de novembro de 1966; e dá outras providências. Diário Oficial União. 27 set 2019.

27. Agência Nacional de Vigilância Sanitária - Anvisa. Instrução normativa $\mathrm{N}^{\circ} 16$, de 26 de abril de 2017. Dispõe sobre a lista de classificação nacional de atividades econômicas (CNAE) classificadas por grau de risco para fins de licenciamento sanitário. Diário Oficial União. 27 abr 2017.

28. Pullon S, Morgan S, Macdonald L, McKinlay E, Gray B. Observation of interprofessional collaboration in primary care practice: a multiple case study. J Interprof Care. 2016;30(6):787-94. https://doi.org/10.1080/13561820.2016.1220929

29. Agreli HF, Peduzzi N, Bailey C. Contributions of team climate in the study of interprofessional collaboration: a conceptual analysis. J Interprof Care. 2017;31(6):679-84. https://doi.org/10.1080/13561820.2017.1351425

30. Agência Nacional de Vigilância Sanitária - Anvisa. Conferência nacional de vigilância sanitária: relatório final. Brasília: Agência Nacional de Vigilância Sanitária; 2001.

31. O’Dwyer G, Reis DCS, Silva LLG. Integralidade, uma diretriz do SUS para a vigilância sanitária. Cienc Saude Coletiva. 2010;15(Supl.3):3351-60. https://doi.org/10.1590/S1413-81232010000900010

Contribuição dos Autores

Sales Neto MR, Gondim APS - Concepção, planejamento (desenho do estudo), aquisição, análise, interpretação dos dados e redação do trabalho. Paiva FM, Sales Neto MR, Lôbo CDA - Interpretação dos dados e redação do trabalho. Todos os autores aprovaram a versão final do trabalho.

Conflito de Interesse

Os autores informam não haver qualquer potencial conflito de interesse com pares e instituições, políticos ou financeiros deste estudo.

Licença CC BY-NC atribuição não comercial. Com essa licença é permitido acessar, baixar (download), copiar, imprimir, compartilhar, reutilizar e distribuir os artigos, desde que para uso não comercial e com a citação da fonte, conferindo os devidos créditos de autoria e menção à Visa em Debate. Nesses casos, nenhuma permissão é necessária por parte dos autores ou dos editores. 